\title{
Vloga glagolske perifraze haber de + nedoločnik $v$ časovni strukturi romana Sto let samote
}

Ključne besede: glagolska perifraza, časovnost, modalnost, haber de + nedoločnik

$1 \quad$ glagolski perifrazi haber de + nedoločnik: med naklonskostjo in časovnostjo

Glagolska perifraza haber de + nedoločnik je tako po obliki in pomenu kot tudi po sintaktičnem opisu prava glagolska perifraza, ${ }^{1}$ sestavljena iz dveh glagolov, popolnoma gramatikaliziranega pomožnika haber in glavnega glagola v nedoločniku, ki ju povezuje predlog de. Glagol haber je v sodobni španščini edini pomožni glagol pri sestavljenih glagolskih paradigmah - za razliko od nekaterih drugih romanskih jezikov in srednjeveške španščine, kjer se je za določene glagole v sestavljenih paradigmah uporabljal tudi pomožnik ser. Haber je v španščini izgubil svoj leksikalnosemantični pomen posedovanja (imeti, posedovati), ki ga je prevzel glagol tener. Haber se kot pomožnik uporablja tudi v dveh glagolskih perifrazah: haber de + nedoločnik in haber $q u e+$ nedoločnik (v3. osebi ednine). V glagolski perifrazi haber de + nedoločnik glavni glagol ne pozna nobenih leksikalnih omejitev, kar pomeni, da je glavni glagol lahko katerikoli, večinoma se nahaja v obliki enostavnega nedoločnika, čeprav je možna tudi sestavljena oblika, predvsem v epistemskem pomenu verjetnosti in domneve: «No han de haber llegado porque las persianas siguen bajadas» (García Fernández, 2006, 166).

Prevladujoča vrednost te glagolske perifraze je modalna, uporablja se predvsem za izražanje obveznosti, dolžnosti in nujnosti (»Han de salir ya. El teatro se va a cerrar« (García Fernández, 2006, 164)). Modalni pomen obveznosti in nujnosti pa je pogosto povezan s časovnim pomenom zadobnosti. Tako je v stari kastiljščini z združitvijo nedoločnika glagola in pomožnika haber v sedanjiku indikativa nastala glagolska

1 Glagolsko perifrazo lahko z oblikoslovno-skladenjskimi in semantičnimi merili opredelimo kot nedeljivo enoto dveh glagolov, ki skupaj tvorita povedek. Prvi glagol ima vlogo pomožnika, čeprav ne izgubi vedno svojega pomena, drugi, glavni glagol, pa je v nedoločniku, gerundiju ali deležniku. Izjemo tvorijo posebne kopulativne glagolske perifraze (npr. ir y + glagol). Pomožnik in glavni glagol se lahko povezujeta tudi s predlogom ali veznikom. Vsi sestavni deli glagolske perifraze skupaj tvorijo semantično in skladenjsko enoto, ki ima svoj pomen in vlogo v besedilu. 
paradigma futuro simple (enostavni prihodnjik). ${ }^{2}$ Že v vulgarni latinščini je klasične latinske oblike futura (amabo, audiam) nadomestil nedoločnik, ki mu je sledil glagol habere (imeti) v prezentu: cantare + habeo > cantar + he $>$ cantaré. Na začetku je bila ta glagolska paradigma glagolska perifraza $\mathrm{z}$ modalnim pomenom obveznosti ( $\mathrm{v}$ srednjem veku sta se obe komponenti pogosto pisali narazen, encontrar te he namesto te encontraré), ki ga je postopoma izgubila in pridobila časovni pomen za prihodnost oziroma zadobnost. Cantar he je najprej pomenilo obveznost (v sedanjosti) za prihodnje dejanje, to, kar danes pomeni he de cantar. Ker je ta oblika sčasoma izgubila pomen obveznosti in nujnosti, je nastala nova glagolska perifraza s tem pomenom, haber de + nedoločnik, za katero velja, da je ena najstarejših španskih glagolskih perifraz, ki se pogosteje rabi v književni španščini, redkeje pa v pogovornem jeziku.

El tiempo venidero de una acción se expresaba por la obligación presente de realizarla: amar he significaba primitivamente he de amar. A medida que en amaré se fue sintiendo únicamente el valor de futuro, hubo que echar mano de un medio que significase obligación en cualquier tiempo, y para ello se inició y extendió el uso de haber de cantar (he de cantar) frente a cantaré (cantar he) (Gili Gaya, 1976, 112).

Raba haber de + nedoločnik s časovno vrednostjo prihodnjika je zelo pogosta $\mathrm{v}$ mehiški, srednjeameriški in antilski španščini (»A continuación hemos de oír la segunda sinfonía de ... con el sentido de '... vamos a oír, oiremos ..." (NGLE, 2009, 2146-2147)), pa tudi v dialektih na severovzhodu Španije (NGLE, 2009, 2146).

Naklonski pomen se pri haber de + nedoločnik pogosto prepleta s časovnim pomenom za prihodnost, če je pomožnik v sedanjiku (»Ha de llover más para que no haya sequía en este verano« (García Fernández, 2006, 164)). Časovni pomen za prihodnost oziroma zadobnost lahko celo zabriše modalni pomen obveznosti, nujnosti (»Tarde o temprano se ha de saber la verdad sobre este caso « (García Fernández, 2006, 164)) ali pa se oba pomena, časovni in modalni, zlijeta v epistemski pomen verjetnosti, domneve (»Llámala por teléfono que ha de estar en casa« (Markič, 2010, 161)). Zanimiva je tudi raba te glagolske perifraze $\mathrm{v}$ pogovornem jeziku, predvsem $\mathrm{v}$ vzkličnih povedih, kjer poudarja trditev ali zanikanje s pomenskim odtenkom presenečenja, zavrnitve, ogorčenosti ("¿Sabes hablar chino? -iQué he de saber!; ¿Le pillaron robando; ¡quién lo había de decir!« (Markič, 2010, 160)).

\section{O pripovedni strukturi romana Sto let samote}

Cien años de soledad es una novela total sobre todo porque pone en práctica el utópico designio de todo suplantador de Dios: describir una realidad total,

2 Podobno je z združitvijo nedoločnika glagola in pomožnika haber v imperfektu nastala glagolska paradigma condicional simple (enostavni pogojnik): cantar + había, hía > cantaría). 
enfrentar a la realidad real una imagen que es su expresión y negación. Esta noción de totalidad, tan escurridiza y compleja, pero tan inseparable de la vocación del novelista, no sólo define la grandeza de Cien años de soledad: da también su clave. Se trata de una novela total por su materia, en la medida que describe un mundo cerrado, desde su nacimiento hasta su muerte y en todos los órdenes que lo componen -el individual y el colectivo, el legendario y el histórico, el cotidiano y el mítico-, y por su forma, ya que la escritura y la estructura tienen, como la materia que cuaja en ellas, una naturaleza exclusiva, irrepetible y autosuficiente (Vargas Llosa, 1971, 480).

Sto let samote kolumbijskega pisatelja in nobelovega nagrajenca Gabriela Garcíe Márqueza opisuje sto let družine Buendía in naselja Macondo. Vse zgodbe o Macondu in Buendíjevih, ki so razpršene po Garcíjevih romanih in kratkih zgodbah, napisanih pred tem romanom, ${ }^{3}$ najdejo svoj smisel in zaključek v njem. Svet, ki ga ustvarja Gabriel García Márquez, se bohoti, napihuje, razmnožuje. Igra s časom in prostorom, preplet usod brezštevilnih junakov ter vdiranje čudežnega in fantastičnega v vsakdanjost spremlja presenečenega bralca od začetka do konca, ko se saga o Macondu in družini Buendía izčrpa in sesede sama vase ter živi naprej kot mit.

Že prvi stavek v romanu razkrije vsevednega pripovedovalca, ki pripoveduje v tretji osebi ednine. Vsevedni pripovedovalec je vse do konca romana zunaj pripovedi, je neviden, dogajanja opazuje od zunaj in jih zaobjema globalno. Ker pozna potek dogodkov, se poigrava s časom, je gospodar pripovednega časa ter se sprehaja naprej in nazaj po pripovedi, ni ga čutiti, le sem ter tja je mogoče opaziti znamenje, da je prisoten. Pripoved teče linearno, od nastanka Maconda pa vse do njegovega konca, vendar se pripovedovalec zelo pogosto poslužuje pripovednih tehnik flash back (pogled nazaj) in flash forward (pogled naprej). Tako je že prvi stavek v romanu pogled naprej, neke vrste napoved, ki projicira dejanje, hkrati pa se v istem hipu skozi spomine junaka obrača daleč nazaj v preteklost. Vsevedni pripovedovalec, pripovedovalec bog, kot ga imenuje Vargas Llosa $(1971,539)$, se na koncu knjige zlije v pripovedovalca junaka, kajti šele v zadnjem odstavku bralec odkrije, da je pripovedovalec tudi junak pripovedi. Prefinjen preskok v perspektivi pripovedovalca se ne kaže v spremembi tretje osebe $\mathrm{v}$ prvo, kot bi pričakovali, ampak pripoved še naprej teče v tretji osebi; bralcu se na koncu razkrije skrivnostni pripovedovalec Aureliano Babilonia, ki bere Melquíadesov rokopis. Tako je bralec vseskozi bral enako zgodbo, kot jo je bral do tistega trenutka Aureliano Babilonia. Pripovedovalec ni bil vsevedni pripovedovalec, temveč junak zgodbe, ki

3 V Sto let samote se pojavljajo junaki in teme prej napisanih kratkih zgodb in romanov. Nekatere zgodbe, začete v prejšnjih delih, se tu razpletejo, druge so le bežno omenjene. Tako se v Sto let samote sprehajajo junaki iz del La Hojarasca (Odvrženi), La Mala Hora (Huda ura) in Los funerales de la Mamá Grande (Pogreb velike mame). V tem romanu so prisotni tudi posamezni prizori ali teme drugih zgodb, kot na primer El coronel no tiene quien le escriba (Polkovnik nima nikogar, ki bi mu pisal), Rosas Artificiales (Umetne vrtnice) itd. 
posredno pripoveduje zgodbo, beroč rokopis, napisan znotraj pripovedi. V resnici je pripovedovalec romana Sto let samote Melquíades, saj njegov rokopis predstavlja zgodbo, ki jo beremo. Pripovedovalec, junak in bralec se znajdejo na isti točki.

Así, al final, sabemos que el narrador era pieza integrante de la realidad ficticia, es decir, alguien (algo: los manuscritos) que va a desaparecer con Macondo, que va a ser destruido junto con lo narrado. La profecía de Melquíades y sus manuscritos no han sido forjados en una exterioridad sino en el seno mismo de la realidad ficticia. En el instante en que el narrador y lo narrado coinciden, ambos desaparecen (Vargas Llosa, 1971, 541).

Prvi in zadnji stavek romana se dopolnjujeta. Začetek in konec se stikata. Ko Aureliano Babilonia odkrije, da bere tisto, kar ravnokar doživlja, se zave, da se uresničuje Melquíadesova prerokba in da doživlja zadnje trenutke življenja, pa ne samo svojega, temveč tudi življenja družine Buendía in Maconda.

Sin embargo, antes de llegar al verso final ya había comprendido que no saldría jamás de ese cuarto, pues estaba previsto que la ciudad de los espejos (o los espejismos) sería arrasada por el viento y desterrada de la memoria de los hombres en el instante en el que Aureliano Babilonia acabara de descifrar los pergaminos, y que todo lo escrito en ellos era irrepetible desde siempre y para siempre, porque las estirpes condenadas a cien años de soledad no tenían una segunda oportunidad sobre la tierra (García Márquez, 1986, 325).

Samozadostnost in celovitost sveta se zrcalita $\mathrm{v}$ pripovedni strukturi romana. Ko romaneskni svet izgine, izgine z njim tudi pripovedovalec: «De este modo, la estructura refleja la gran ambición de la materia: describir una realidad hasta agotarla, ser su propio principio y su fin» (Vargas Llosa, 1971, 543).

$\mathrm{V}$ tem samozadostnem in vseobsegajočem svetu se tudi čas obrača drugače. Pripovedni čas (čas, v katerem teče pripoved) in pripovedovalčev čas (čas, ko pripovedovalec pripoveduje zgodbo) sta vse do konca različna. Oba časa se zlijeta, ko se pripovedovalec poistoveti $\mathrm{z}$ enim od junakov zgodbe.

Kljub prepletanju časovnih dimenzij in neštetim podatkom ima roman strogo strukturo. Tvori ga dvajset skoraj enako dolgih nenaslovljenih poglavij. Eno ali več poglavij, ki pa niso nujno zaporedna, tvori pripovedno enoto, ki predstavlja zaokroženo celoto v življenju junakov ali v zgodovini Maconda. Pripovedovalec obvladuje vsako enoto posebej, tako kot obvladuje celoto. Na začetku posamezne enote je običajno opisan osrednji dogodek, ki pa je kronološko zadnji - enota se torej začne s pogledom naprej, nato se pripovedovalec ozre nazaj v bližnjo ali daljno preteklost, od tam naprej pa se pripoved odvija linearno, dokler ne doseže na začetku navedenega dogodka. Tako se krog zapre in epizoda »se ugrizne v rep«: »El episodio se muerde la cola, comienza 
y termina en el mismo sitio, sugiere esa idea de totalidad, de cosa acabada y suficiente que infunde el círculo« (Vargas Llosa, 1971, 550).

Pripovedovalec po svoji volji obrača kolo časa. Vargas Llosa (1971) je časovno strukturo romana opisal kot veliki krog, sestavljen iz številnih manjših krogov, ki se nahajajo eden znotraj drugega, si včasih sledijo, drugič pa se sekajo ali nalagajo eden na drugega. Čeprav pripoved napreduje kronološko, se zgodovinski čas prepleta z mitskim, krožnim časom. Kot da se bojujeta oba časa: večni, krožni čas in linearni, minljivi zgodovinski čas. Po eni strani občutek, da se vse ponavlja in kroži, po drugi strani pa zavest, da čas teče naprej in da ni poti nazaj. Tudi zadnji stavek priča, da na koncu prevlada neusmiljeni kronološki čas: Macondo doživi svoj padec in konec.

No había ningún misterio en el corazón de un Buendía que fuera impenetrable para ella, porque un siglo de naipes y de experiencias le había enseñado que la historia de la familia era un engranaje de repeticiones irreparables, una rueda giratoria que hubiera seguido dando vueltas hasta la eternidad, de no haber sido por el desgaste progresivo e irremediable del eje (García Márquez, 1986, 309-310).

\section{O vlogi glagolske perifraze haber de + nedoločnik $\checkmark$ romanu}

Temeljna tema romana Sto let samote je soočanje teh dveh časov: cikličnega, mitskega, krožnega, večno ponavljajočega se časa in zgodovinskega, za človeško življenje realnega, linearnega časa. Časovnima dimenzijama ustrezata tudi dva prostora, mitski in realni prostor. Igra in preplet obeh časovnih dimenzij v romanu sta prikazana $\mathrm{z}$ različnimi jezikovnimi sredstvi, predvsem pa z glagolskimi paradigmami in glagolskimi perifrazami.

Z haber de + nedoločnik, s pomožnim glagolom v imperfektu, pripovedovalec napoveduje, kaj se bo zgodilo. $\mathrm{Z}$ glagolsko perifrazo $\mathrm{v}$ imperfektu je izražena zadobnost (futuro del pasado) s pomenskim odtenkom neizogibnosti, usodnosti. Vsevedni pripovedovalec napoveduje dogodke pripovednega sveta in na neki način prerokuje. Glagolski perifrazi vrste haber de + nedoločnik in ir a + nedoločnik imata v delih Gabriela Garcíe Márqueza poseben preroški, napovedovalni, najpogosteje zločest pomen. Slovenski prevod prvega stavka v romanu Sto let samote (»Mnogo let zatem, ko je čakal, da ga ustrele, se je polkovnik Aureliano Buendía spomnil tistega daljnega popoldneva, ko ga je oče popeljal gledat led « (García Márquez, 1978, 7) je $\mathrm{v}$ pretekliku (se je spomnil) in ne odraža pomena usodnosti, prerokbe, ki jo izraža glagolska perifraza. Čar igre s časom, ki ga izžareva izvirnik, se v slovenskem besedilu nekoliko zakrije. 
Prvi stavek je za razumevanje sveta Gabriela Garcíe Márqueza, za ustvarjanje vzdušja pripovednega sveta, zelo pomemben. ${ }^{4}$ Roman se prične s pogledom naprej, vendar se pogled takoj obrne daleč nazaj v preteklost: od tam pa pripoved teče naprej v običajnem zaporedju. V prvem stavku romana je s skokom naprej (muchos años después) dogajanje prestavljeno na sredo pripovedi: gre za napoved trenutka, ko bo Aureliano Buendía stal pred strelnim vodom - kar se v pripovedi zgodi precej kasneje in se spomnil svojega otroštva. Na tej točki se pripoved obrne nazaj v daljno preteklost (aquella tarde remota en que su padre lo llevó a conocer el hielo). Od tod teče pripoved po naravnem časovnem zaporedju. Pripovedovalec z opisom Maconda dogajanje umesti v tisti daljni čas, riše ozadje, opisuje okoliščine, niza ponavljajoča se dogajanja (era, se precipitaban, era, carecían, había que, plantaba, daban), izražena v imperfektu, $s$ stališča aspektualnosti osvetljena kurzivno, posamezni dogodki na začetku in koncu pa so osvetljeni globalno in so torej v enostavnem preteritu (llevó, llevaron).

Muchos años después, frente al pelotón de fusilamiento, el coronel Aureliano Buendía había de recordar aquella tarde remota en que su padre lo llevó a conocer el hielo. Macondo era entonces una aldea de veinte casas de barro y cañabrava construidas a la orilla de un río de aguas diáfanas que se precipitaban por un lecho de piedras pulidas, blancas y enormes como huevos prehistóricos. El mundo era tan reciente, que muchas cosas carecían de nombre, y para mencionarlas había que señalarlas con el dedo. Todos los años, por el mes de marzo, una familia de gitanos desarrapados plantaba su carpa cerca de la aldea, y con un grande alboroto de pitos y timbalas daban a conocer los nuevos inventos. Primero llevaron el imán (García Márquez, 1986, 9).

Prvo poglavje je posvečeno opisu dogodkov nekaj let pred tistim trenutkom, ko je Aureliana Buendío oče popeljal v ciganski šotor, da bi mu pokazal led. Ta trenutek je na koncu poglavja. Aurelianovo spominjanje tega dogodka, ki ga uvede glagolska perifraza había de recordar, sproži niz opisov iz začetnega življenja Maconda ter s tem daje pripovedi časovni in prostorski okvir.

Strelni vod, ki naj bi usmrtil polkovnika Aureliana Buendío, se pojavi večkrat v pripovedi v okviru pogleda naprej. Aureliana Buendío zadnji hip reši José Arcadio, tako da se napovedana smrt tokrat ne uresniči.

4 Prvi stavek je za Garcío Márqueza izredno pomemben:

-En general a la primera frase de un libro le asignas mucha importancia. Me dijiste que a veces te llevaba más tiempo escribir esta primera frase que todo el resto. ¿Por qué?

-Porque la primera frase puede ser el laboratorio para establecer muchos elementos de estilo, de la estructura y hasta de la longitud del libro (García Márquez, 1983, 27).

$[\ldots]$

- ¿Cuál fue para ti el momento más difícil de la novela?

-Empezar. Recuerdo muy bien el día en que terminé con mucha dificultad la primera frase, y me pregunté aterrorizado qué carajo vendría después (García Márquez, 1983, 80). 
En el daguerrotipo familiar, el único que existió jamás, Aureliano apareció vestido de terciopelo negro, entre Amaranta y Rebeca. Tenía la misma languidez y la misma mirada clarividente que había de tener años más tarde frente al pelotón de fusilamiento (García Márquez, 1986, 47).

Aureliano, vestido de paño negro, con los mismos botines de charol con ganchos metálicos que había de llevar pocos años después frente al pelotón de fusilamiento, tenía una palidez intensa y una bola dura en la garganta cuando recibió a su novia en la puerta de la casa y la llevó al altar (García Márquez, 1986, 70).

Tudi Arcadio podoživlja svojo mladost, ko stoji pred strelnim vodom, in tudi za to podoživljanje pripovedovalec uporabi tehniki flash forward in flash back, le da se v tem primeru usmrtitev uresniči.

Años después frente al pelotón de fusilamiento, Arcadio había de acordarse del temblor con que Melquíades le hizo escuchar varias páginas de su escritura impenetrable, que por supuesto no entendió, pero que al ser leídas en voz alta parecían encíclicas cantadas (García Márquez, 1986, 63).

Pocos meses después, frente al pelotón de fusilamiento, Arcadio había de revivir los pasos perdidos en el salón de clases, los tropiezos contra los escaños, y por último la densidad de un cuerpo en las tinieblas del cuarto y los latidos del aire bombeado por un corazón que no era el suyo (García Márquez, 1986, 95).

Tik pred smrtjo junaki v spominu podoživljajo (habia(n) de recordar) trenutke iz svojega življenja, pripoved se prestavi časovno nazaj:

Años después, en su lecho de agonía, Aureliano Segundo había de recordar la lluviosa tarde de junio en que entró en el dormitorio a conocer a su primer hijo (García Márquez, 1986, 148).

Z glagolsko perifrazo había de + nedoločnik se običajno napovedujejo usodni dogodki v življenju ali spominjanje usodnih dogodkov, ki so junake romana tako zaznamovali, da so postali obsedeni z njimi. Ti dogodki so $\mathrm{v}$ spominu pridobili tragično moč.

Amaranta Úrsula y el pequeño Aureliano habían de recordar el diluvio como una época feliz (García Márquez, 1986, 257).

Los niños habían de recordar por el resto de su vida la augusta solemnidad con que su padre se sentó a la cabecera de la mesa, temblando de fiebre, devastado por la prolongada vigilia y por el encono de su imaginación, y les reveló su descubrimiento:

-La tierra es redonda como una naranja (García Márquez, 1986, 12). 
Los niños se asombraron con sus relatos fantásticos. Aureliano que no tenía entonces más de cinco años, había de recordarlo por el resto de su vida como lo vio aquella tarde, sentado contra la claridad metálica y reverberante de la ventana, alumbrando con su profunda voz de órgano los territorios más oscuros de la imaginación, mientras chorreaba por sus sienes la grasa derretida por el calor. José Arcadio, su hermano mayor, había de transmitir aquella imagen maravillosa, como un recuerdo hereditario a toda su descendencia (García Márquez, 1986, 13).

José Arcadio in neki deček sta edina preživela pokol delavcev in se ne moreta znebiti spomina na ta dogodek. Podobe pokola in dolgih vlakov, ki so trupla odvažali k morju, ju neprestano spremljajo. Pripovedovalec napoveduje, da José Arcadio in deček ne bosta nikoli pozabila, kar sta doživela. V zgledu na str. 239 je obsedenost s spominom na tragični dogodek podana $\mathrm{z}$ dvojno glagolsko perifrazo, s katero se izražata ponavljalnost in trajanje: haber de + nedoločnik in seguir + gerundij, v zgledu na str. 240-241 pa je ponavljanje poudarjeno s prislovom todavía.

Muchos años después, ese niño había de seguir contando, sin que nadie se lo creyera, que había visto al teniente leyendo con una bocina de gramófono el Decreto Número 4 del Jefe Civil y Militar de la provincia (García Márquez, 1986, 239).

Muchos años después, el niño había de contar todavía, a pesar de que los vecinos seguían creyéndolo un viejo chiflado, que José Arcadio Segundo lo levantó por encima de su cabeza, y se dejó arrastrar, casi en el aire, como flotando en el terror de la muchedumbre, hacia una calle adyacente (García Márquez, 1986, 240-241).

Glagolska perifraza había de + nedoločnik, ki se v romanu pojavlja kot ponavljajoča se magična formula, neke vrste prerokba, izhaja iz globalnega pogleda vsevednega pripovedovalca, ki vnaprej ve, kaj se bo dogodilo:

El tren inocente amarillo que tantas incertidumbres y evidencias, y tantos halagos y desventuras y tantos cambios, calamidades y nostalgias había de llevar a Macondo (García Márquez, 1986, 178).

Los acontecimientos que habian de darle el golpe mortal a Macondo empezaban a vislumbrarse cuando llevaron a la casa al hijo de Meme Buendía (García Márquez, 1986, 231).

Las casas de madera, las frescas terrazas donde transcurrían las serenas tardes de naipes, parecían arrasadas por una anticipación del viento profético que años después había de borrar a Macondo de la faz de la tierra (García Márquez, 1986, 260). 


\section{$5 \quad$ Sklepne misli}

Glagolska perifraza haber de + nedoločnik je močno ekspresivno obarvana zaradi vrednosti, ki jih izraža: časovne (zadobnost), aspektualne (faze dejanja, ko je dejanje tik pred uresničitvijo in ga ne moremo več preprečiti) ter modalne, kjer je prisotna ideja obveznosti in nujnosti ter nakazuje dogajanje, ki se mu ne moremo upreti ali ga zaustaviti. Glagolska perifraza (s pomožnikom v imperfektu) ima torej preroško funkcijo, ki jo Gabriel García Márquez pogosto uporablja v svojih delih in se poigrava s slogovnimi možnostmi, ki mu jih ponuja. Vsevedni pripovedovalec igra vlogo boga (Vargas Llosa, 1971), saj ustvarja pripovedni svet, z njim manipulira in se poigrava s časom. Ker pripoved vidi v celoti, lahko dogodke napove že mnogo prej, preden se dejansko uresničijo v pripovedi. Kot zunanji opazovalec ve, kako se bo razpletla zgodba, ki jo pripoveduje, in zato vnaša svojo prisotnost in vsevednost tako, da $s$ pomočjo te in nekaterih drugih glagolskih perifraz in jezikovnih sredstev obrne pogled naprej. $\mathrm{V}$ tej rabi ima glagolska perifraza tudi močno ekspresivno vrednost, saj daje občutek neizbežnosti usode, ki je tako zelo prisoten v delih Garcíe Márqueza. Bralec dobi občutek, kot da je že vse vnaprej določeno in da vse kroži po že utrjenih tirnicah.

\section{Literatura}

Fernández de Castro, F., Las perífrasis verbales en el español actual, Madrid 1999.

García Fernández, L., Diccionario de perífrasis verbales, Madrid 2006.

García Márquez, G., Sto let samote, Ljubljana 1978.

García Márquez, G., El olor de la guayaba, Conversaciones con Plinio Apuleyo Mendoza, Bogotá 1983.

García Márquez, G., Cien años de soledad, Bogotá 1986.

Gili Gaya, S., Curso Superior de sintaxis española, Barcelona 1961.

Gómez Torrego, L., Perífrasis verbales. Sintaxis, semántica y estilística, Madrid 1988.

Markič, J., Perspectivas temporales y aspectuales en las obras narrativas de Gabriel García Márquez, Linguistica 38/2, 1998, str. 131-148.

Markič, J., El verbo en español. Aspectos teóricos de la morfosintaxis del verbo español, Ljubljana 2010.

Real Academia Española, Nueva gramática de la lengua española, Madrid 2009, str. 2105-2222.

Vargas Llosa, M., García Márquez: Historia de un deicidio, Barcelona-Caracas 1971. 
Jasmina Markič

\section{The role of the verbal periphrasis haber de + infinitive in the temporal structure of the novel One Hundred Years of Solitude}

Keywords: verbal periphrasis, temporality, modality, haber de + infinitive

The article analyzes some temporal and aspectual values (past future, imminence of an event) intermingled with modal values (epistemic values of obligation, necessity and probability) of the Spanish verbal periphrasis haber de + infinitive which convey very special stylistic values and meanings in Gabriel García Márquez's novel One Hundred Years of Solitude. Haber de + infinitive (in the imperfect tense of the indicative: habia de + infinitive) introduces the first sentence and activates the events in the novel, giving them a particular temporal and spatial frame. Through the narrative techniques of flashback and flash forward - present in this novel in which the dominant theme is time and the inevitable repetition of history in Macondo - the above-mentioned verbal periphrasis plays an important role in signalling events that can be neither avoided nor stopped. With its strong expressive force, and due to its basic temporal and modal meanings, the verbal periphrasis haber $d e+$ infinitive has a premonitory function in the novel: it predicts fatal events in the lives of the inhabitants of Macondo - inhabitants who are controlled by their pasts and the complexity of time - and in the history of the town, which seems to be doomed and predetermined in its very existence. 